\title{
Pedal Operated Water Filtration System (Mobifilt)
}

\author{
Sanjay N.Havaldar ${ }^{*}$, Altaf Somani ${ }^{\ddagger}$, Anusha Pikle ${ }^{\ddagger}$, Yash Siriah $^{\ddagger}$ and Samiksha Patil ${ }^{\ddagger}$ \\ †Department of Mechanical Engineering, SSPU, Pune, India \\ , \#Department of Mechanical Engineering, Shri Savitribai Phule Pune University, Pune, India \\ Accepted 02 March 2016, Available online 15 March 2016, Special Issue-4 (March 2016)
}

\begin{abstract}
This paper analyzes the design of a pedal operated water filtration system to be used by local dwellers. It works on the principle of compression and sudden release of a tube by creating negative pressure in the tube and this vacuum created draws water from the sump into the pump while rollers push the water through to the filter where adsorption takes place to purify the water. The design comprises of a peristaltic pump powered by pedaling, a filter and hose or flexible tube. As the operator sits on the seat and pedals, the pedal crank transfers the motion to the rotor thus the rollers and the tube is squeezed by the set of rollers to move the fluid. This design will reduce the labour, cost and weariness caused by transporting and sanitizing drinkable water for use.
\end{abstract}

Keywords: Filtration System, Pedal crank, Peristaltic pump, Sump, Local dwellers, pure water

\section{Introduction}

Safe drinking-water and adequate sanitation services to all is perhaps the greatest development failure of the $21^{\text {st }}$ century. The most egregious consequence of this failure is the high rate of mortality among young children from preventable water-related-diseases. Water is essential to sustain life, and a satisfactory (adequate, safe and accessible) supply must be available to all.

Improving access to safe drinking-water can result in tangible benefit to health. Nearly, one billion people suffer needlessly without access to safe drinking water and over five thousand children die each day because of water related diseases. Water-related diseases: caused by insect vectors, especially mosquitoes, that breeds in water; include dengue, filariasis, malaria, onchocerciasis, trypanosomiasis and yellow fever. (Peter H.G., 2002). Drinkable water sources are distant from most villages in India. Women and children especially spends hours of labour just to meet the basic needs of their families walking five miles and more to nearby towns just to have access to drinkable (purified) water. Some well to do inhabitants in these villages travel long distances with motor bikes and trucks which consume fuel and pollute the air.

Moreover, a family of five needs a minimum of fifteen gallons of water each day. The only way to sanitize the stream water available to these villages is by boiling which also consumes precious resources and contributes to deforestation since the only source of

*Corresponding author: Sanjay N.Havaldar energy for boiling this much water is firewood and charcoal (Payment and Hunter, 2001; Howard, 2006). However, a number of studies from low-income countries have indicated that improved access to water - and the resulting increases in the quantity of water or time used for hygiene - are the determining factors of health benefits, rather than improvements in water quality (Curtis and Cairncross, 2003).

The objective of this work is to design a mechanism to be used with water filter to supply purified water for villages and remote places by harnessing the human pedal power.

\section{Materials and Methods}

A bicycle is used for this purpose with the general arrangement as shown in Fig. 1. The type of pump selected for this work is peristaltic pump. A peristaltic pump is a positive displacement pump used for pumping a variety of fluids. The fluid is contained within a flexible tube fitted inside a circular pump casing. A rotor in the form of plate with a number of "rollers", "shoes" or "wipers" is attached to the external circumference and connected to the sprocket. As the rollers compress the hose and move away from the inlet a vacuum is created drawing in liquid. The rollers work together to capture liquid between the pinched areas of the tube and move the liquid toward the discharge. (A.S. Akinwonmi, 2012) The front roller leaves the hose, opening the captured area whiles the back roller pushes the liquid out the discharge. This process is called peristalsis and is used in many 
biological systems such as the gastrointestinal tract. This type of pump is selected for this work because of the following characteristics: because of its wider range of operating speeds, thus efficient at both high and low revolution per minutes (rpm), dry running/self-priming/seal less, creation of high vacuum for suction lift application, smooth passage through the pump thus no checks or obstructions, relatively high discharge pressure.

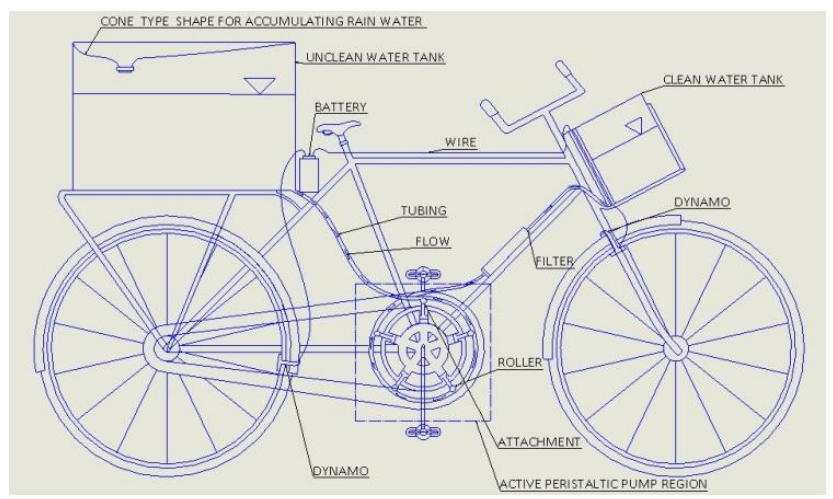

Fig.1 General arrangement of the unit.

\subsection{Principle of Operation}

This design is composed of a peristaltic pump powered by paddling, a carbon filter and hose or flexible tube as shown in Fig.1. An operator sits on the seat and pedals, the pedal crank transfer the motion to the rotor thus the rollers. The tube is squeezed by the set of rollers to move the fluid. By constricting the tube and increasing the low-pressure volume, a vacuum is created to pull the liquid into the tube. Once in the pump, the liquid is pushed through the tube by compressing the tube at a number of points in contact with the rollers. The media is moved through the tube with each rotating or oscillating motion. The water is then forced through a filter which removes chemicals, bad taste and smell, pollutants, turbidity and other micro-organisms. The viruses are then killed by the UV powered by the battery charged by using a dynamo or a solar panel making the water now safe and drinkable.

\subsection{Materials Selection}

Peristaltic pump in the design as shown in Fig. 2 consists of a tube which is squeezed by a set of rollers or shoes to move fluid. By constricting the tube and increasing the low-pressure volume, a vacuum is created to pull the liquid into the tube. The material used for the peristaltic pump is mild steel. This material is used for the pump casing, plates, and shaft. The problem most likely to cause damage to the design is corrosion. For this reason to protect the shaft from corrosion it is subjected to hardening.

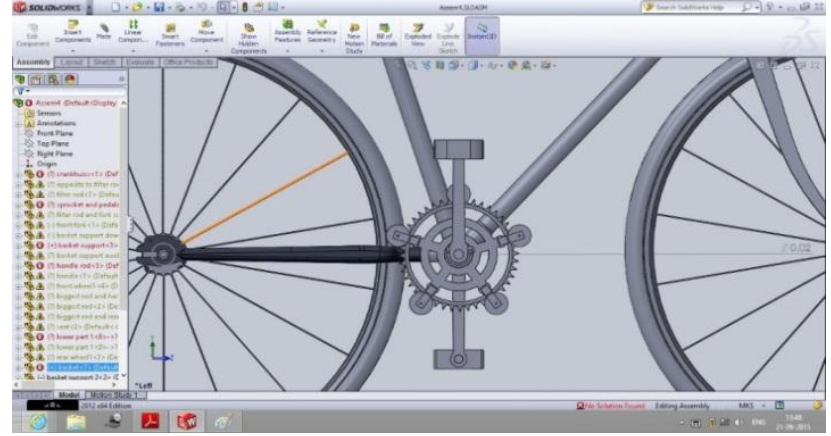

Fig.2 Pictorial view of the proposed design

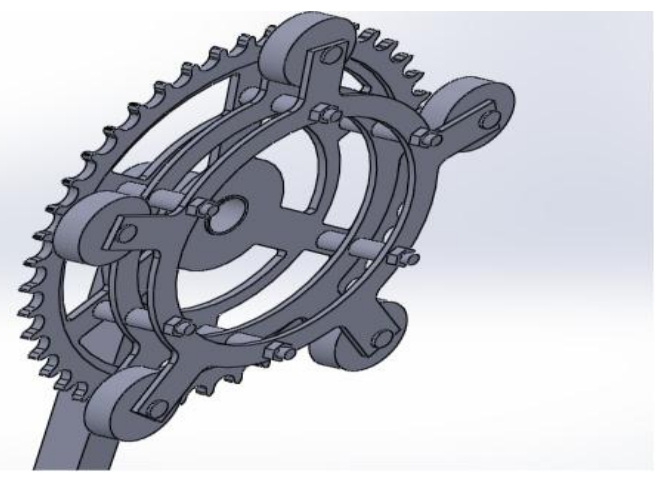

Fig.3 CAD model of the proposed design

\section{Mathematical Modeling}

\section{Physical variables:}

a) Diameter (D) of the casing.

b) Tube diameter (d).

c) Tube length (L).

d) Friction at the pedals.

e) Friction at the axle of the sprocket.

f)Friction where the rollers connect the arms.

g) Rolling friction- where rollers connect the tube.

\section{Dependent Variables:}

a) Flow rate (Q).

b) Rotational speed (N).

c) Power (P).

The physical variables like tube length (L), casing diameter (D), and tube diameter (d) depend on the design and requirements. Also once these are fixed, they cannot be changed.

To establish an analytical model using these parameters, it is necessary to consider the relation among the various parameters. (Garneau C., 2008)

\section{Power Supplied}

It is a function of moment arm (R) and RPM (N). $\mathrm{P}_{\text {supplied }}=\mathrm{P}(\mathrm{R}, \mathrm{N})$ 


\section{Power Required}

It is the sum of power developed due to friction between the rollers and the tube and the power developed by the system.

$$
\begin{aligned}
& \mathrm{P}_{\text {required }}=\mathrm{P}_{\mathrm{f}_{\text {riction }}}+\mathrm{P}_{\text {system }}=\mathrm{P}(\mathrm{L}, \mathrm{D}, \mathrm{d}, \mathrm{N}) \\
& \mathrm{Q}=\mathrm{Q}(\mathrm{D}, \mathrm{d}, \mathrm{N})
\end{aligned}
$$

\subsection{Theoretical Flow Rate Calculations}

The theoretical flow rate is calculated as follows.

Assuming inner diameter of tube $(d)=0.0095 \mathrm{~m}$, casing diameter $(\mathrm{D})=0.23 \mathrm{~m}$.

The volume of water displaced per roller is given as:

Volume displaced per roller $=$ Area of the tube (crosssectional) * (circumference of the casing)

$=\left(\pi \times 0.25 \times \mathrm{d}^{2}\right) \times(\pi \times 0.23)$

$=5.1217 \times 10^{-5} \mathrm{~m}^{3}$

Total volume displaced $\left(\mathrm{V}_{\text {total }}\right)$ for 5 rollers used:

$=($ Volume displaced per roller $)$

$=5.1217 \times 10^{-5} \mathrm{~m}^{3}$

Discharge per occlusion (Q):

Assuming average pedalling speed of human

$$
\begin{aligned}
= & 35 \mathrm{RPM} \quad \ldots \quad(30 \leq \mathrm{N} \leq 40) \\
\mathrm{Q} & =\mathrm{V}_{\text {total }} \times \quad \text { (rotational speed per minute) } \\
& =5.1217 \times 10^{-5} \times(2 \pi N \div 60) \\
& =5.1217 \times 10^{-5} \times[(2 \pi \times 35) \div 60] \\
& =1.18772 \times 10^{-4} \mathrm{~m}^{3} / \mathrm{s}
\end{aligned}
$$

\subsection{Frictional Head Loss}

For a variety of $\mathrm{D}$ and $\mathrm{d}$ and a set $v$ (kinematic viscosity): N, Q, V (average fluid velocity), $R e$ (Reynolds's number), f (friction factor), $\mathrm{H}_{\mathrm{L}}$ (head loss). Variables v, Re, f, H, L and WHP may be found as follows:

Let the diameter of both the suction and delivery tube be equal. For the purpose of this design, the tube is considered to be smooth. Therefore, velocity of flow in the tube is:

$$
\begin{aligned}
\text { Velocity }= & {[(\text { discharge }) \div(\text { area })] } \\
& =\left(1.18772 \times 10^{-4}\right) \div(\pi \times 0.25 \times 0.0152) \\
& =1.675 \mathrm{~m} / \mathrm{s}
\end{aligned}
$$

To decide whether the flow of water in the tube is laminar or turbulent we calculate Reynolds's Number (Re),

$$
\begin{aligned}
\operatorname{Re} & =\left(\begin{array}{l}
\text { Density } \times \text { velocity } \times \\
\text { Hydraulic diameter }
\end{array}\right) \div\left(\begin{array}{l}
\text { dynamic } \\
\text { viscosity of fluid }
\end{array}\right) \\
& =\left(\rho \times \mathrm{v} \mathrm{x} \mathrm{d}_{\mathrm{h}}\right) \div(\mu) \\
& =\left(\mathrm{v} \mathrm{x} \mathrm{d}_{\mathrm{h}}\right) \div(v)
\end{aligned}
$$

Where, kinematic viscosity $v=\mu / \rho$

Kinematic viscosity of water at $20.2^{\circ} \mathrm{C}$ for all practical purposes is considered as $1 \mathrm{~mm} / \mathrm{s}^{2}=10^{-6} \mathrm{~m}^{2} / \mathrm{s}$ Therefore, $v=10^{-6} \mathrm{~m}^{2} / \mathrm{s}$

$$
\begin{aligned}
\mathrm{d}_{\mathrm{h}}= & (4 \mathrm{~A} / \mathrm{P})=\left(4 \pi \times r^{2}\right) \div(2 \pi \times \mathrm{r}) \\
& =2 \mathrm{r} \\
& =\mathrm{d} \text { (duct diameter })
\end{aligned}
$$

Where, $\mathrm{A}=$ area of cross section of duct

$$
\begin{aligned}
& \mathrm{P}=\text { wetted perimeter of duct } \\
& \operatorname{Re}=(\mathrm{v} \mathrm{d}) / v \\
&=(1.675 \times 0.0095) \div\left(10^{-6}\right) \\
&=15912.5
\end{aligned}
$$

Since $\operatorname{Re}>2000$ (flow is turbulent)

Colebrook's equation is used to find the value of friction factor since the flow is turbulent.

Therefore,

$$
\left(\frac{1}{\mathrm{f}}\right)=-2 \times \log _{10}\left[\left(\frac{\mathrm{K}}{\mathrm{d}_{\mathrm{h}}}\right) \times\left(\frac{1}{3.72}\right)+\left(\frac{2.51}{\operatorname{Re} \times \sqrt{\mathrm{f}}}\right)\right]
$$

Where,

$\mathrm{k}=$ absolute roughness $=(0.0015$ to 0.007$) \times 10^{-3} \mathrm{~m}$ for PVC and plastic pipes.

Taking average, therefore, $\mathrm{K}=4.25 \times 10^{-6} \mathrm{~m}$

Thus, $\mathrm{f}=0.0282$

relative roughness $=\left(\frac{\mathrm{k}}{\mathrm{d}_{\mathrm{h}}}\right)=0.00045$

Head lost can be calculated by Darcy Weisbach's equation as

$$
\begin{aligned}
\mathrm{H}_{\mathrm{L}} & =\frac{\mathrm{f} \times \mathrm{l} \times \mathrm{v}^{2}}{2 \times \mathrm{g} \times \mathrm{d}_{\mathrm{h}}} \\
& =\frac{0.0282 \times 1.5 \times 1.6752}{2 \times 9.81 \times 0.0095} \\
& =0.6367 \mathrm{~m}
\end{aligned}
$$

\subsection{Required Power}

The power required to drive the pump depends on the frictional forces and the torque on the arm: 


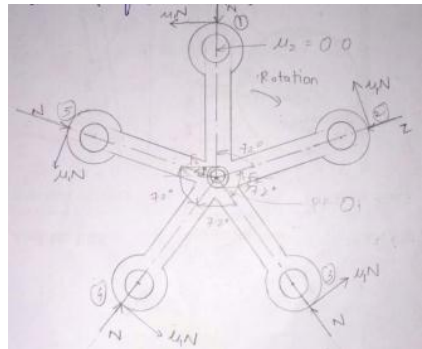

Fig.4 Static analysis of pump

$$
\begin{aligned}
\sum \mathrm{F}_{\mathrm{x}} & =(-\mu \mathrm{N})-\mu \mathrm{N} \cos 72 \\
& +\mu \mathrm{N} \cos 36-\mu \mathrm{N} \cos 72+\mu \mathrm{N} \cos 36 \\
& =2 \mu \mathrm{N}
\end{aligned}
$$

The force needed by the flexible tube choosing thus Tygon ${ }^{\mathrm{TM} X L-60}$ to retract after compression is $200 \mathrm{~N}$ therefore that is the force that will act on the rollers, $\mathrm{N}$ $=200 \mathrm{~N}$. Further, we assume friction coefficient as 0.3.

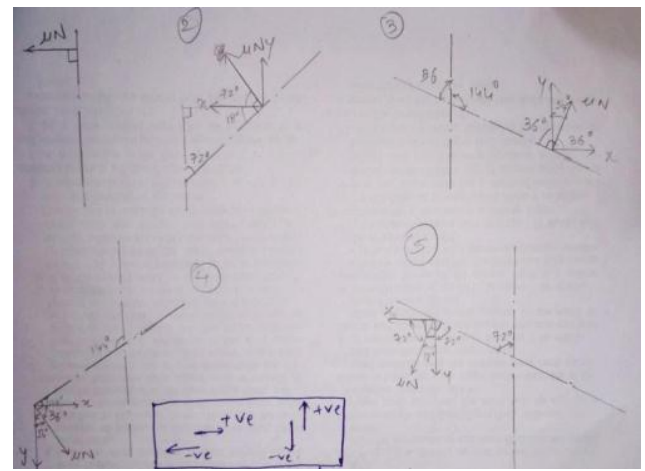

Fig.5 Resolution of forces

$\sum \mathrm{F}_{\mathrm{x}}=120 \mathrm{~N}$

$\sum \mathrm{F}_{\mathrm{y}}=\mu_{1} \mathrm{~N} \sin 72+\mu_{1} \mathrm{~N} \sin 36-\mu_{1} \mathrm{~N} \sin 36-\mu_{1} \mathrm{~N} \sin 72$

$=0$

$$
\mathrm{F}_{1}=\sqrt{\left(\sum \mathrm{F}_{\mathrm{x}}^{2}\right)+\left(\sum \mathrm{F}_{\mathrm{y}}^{2}\right)}
$$$$
=120 \mathrm{~N}
$$

Total torque $\mathrm{T}=\mathrm{T} 1+\mathrm{T} 2=\left(\mathrm{F}_{1} \times \mathrm{r}_{1}\right)+\left(\mathrm{F}_{2} \times \mathrm{r}_{2}\right)$ Where,

$$
\begin{aligned}
& \mathrm{F}_{2}=\mu \mathrm{N}=0.3 \times 200=60 \mathrm{~N} \\
& \mathrm{r} 1=\text { effective radius from the sprocket centre pt. } \mathrm{O} \text { to } \\
& \quad \text { th tube's inner diameter }=0.102 \mathrm{~m} \\
& \mathrm{r} 2=\text { radius of pedal }=0.015 \mathrm{~m} \\
& =\left(120 \times 0.102 \times 10^{-3}\right)+(0.3 \times 200 \times 0.015) \\
& =13.14 \mathrm{Nm} \\
& \mathrm{T}=\mathrm{T} 1+\mathrm{T} 2=13.14 \mathrm{Nm} \\
& \text { Power }=\mathrm{T} \times \omega \\
& =13.14 \times \frac{2 \times \pi \times 35}{60} \\
& =48.1606 \mathrm{~W}
\end{aligned}
$$

Applying Bernoulli's Equation

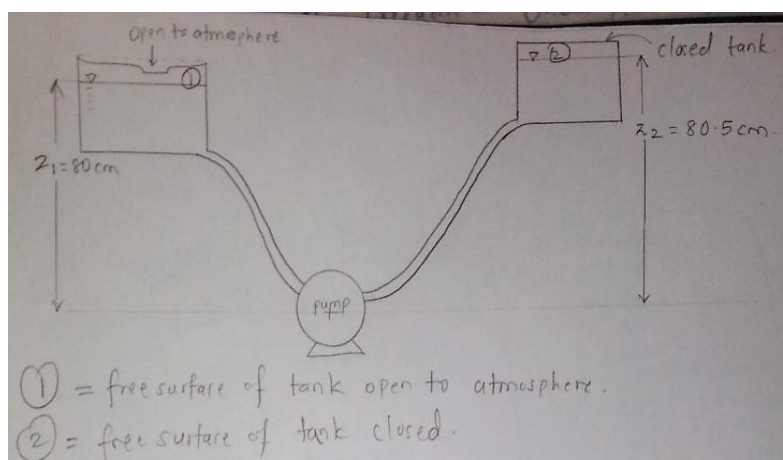

Fig.6 Bernoulli's equation

$$
\begin{array}{r}
\left(\frac{P_{1}}{\rho \mathrm{g}}\right)+\left(\frac{\mathrm{v}_{1}^{2}}{2 \mathrm{~g}}\right)+\mathrm{z}_{1}+\mathrm{H}_{\mathrm{p}}=\left(\frac{P_{2}}{\rho \mathrm{g}}\right)+\left(\frac{\mathrm{v}_{2}^{2}}{2 \mathrm{~g}}\right)+\mathrm{z}_{2} \\
+\Sigma(\text { losses })
\end{array}
$$

There will be no velocity heads at points $1 \& 2$. Therefore, $\mathrm{v}_{1}=\mathrm{v}_{2}=0$. Both points 1 and 2 are exposed to [09] atmosphere therefore the pressure head at both points is zero and datum is the centre of sprocket.

Therefore, $\mathrm{z}_{1}+\mathrm{H}_{\mathrm{p}}=\mathrm{z}_{2}+\Sigma($ losses $)$

$0.8+\mathrm{H}_{\mathrm{p}}=0.85+$

$\left[\begin{array}{l}\mathrm{H}_{\mathrm{L}}+\text { Loss at entry to pipe and filter }+ \text { Loss at exit } \\ \text { through pipe and filter }+ \text { Loss due to bends }+ \\ \text { Pressure head lost in filter }\end{array}\right]$

$0.8+\mathrm{Hp}=0.85+\left[\begin{array}{l}0.6367+\frac{1.6752}{2 \times 9.81} \\ +\frac{4 \times 1.5 \times 1.675}{2 \times 9.81}+\frac{2 \times 1.6752}{2 \times 9.81}+24.94\end{array}\right]$

$\mathrm{Hp}=26.8671 \mathrm{~m}$

Power delivered by pump $=\rho \times \mathrm{g} \times \mathrm{Q} \times \mathrm{H}_{\mathrm{p}}$

$=1000 \times 9.81 \times 1.18772 \times 10^{-4} \times 26.8671$

$=31.304 \mathrm{~W}$

\section{Results and Discussion}

The design was focused on all the processes of conception, invention, visualization, calculation, refinement and specification of details that determine the form of the system. The design has gone under force analysis so that its performance criterion will not fail in any sense. The main physical parameters of the design are determined through the appropriate calculations and practical considerations with reasonable assumptions. It is discovered that the design is simple, cheap, efficient and affordable as 
could be seen from the readily available materials used. Figure 1 shows the setup while figures 2 and 3 show the CAD design and one its components.

It can be seen from the design analysis that the rate of discharge per occlusion is $1.18772 \times 10^{-4} \mathrm{~m}^{3} / \mathrm{s}$ is considered reasonable. The power required to drive the pump is $31.304 \mathrm{~W}$ and the supplied power is $48.1606 \mathrm{~W}$ which are all good and reliable.

\section{Conclusion}

The benefits associated with access to safe drinking water provide a strong argument to increase resource allocations to interventions aimed at further improving the current drinking-water situation, as a key entry point for achieving much wider livelihood benefits.

The pedal operated water filtration system is a new system that is useful in developing countries like India to have daily access to safe drinking water all by harnessing the energy of pedal power.

\section{References}

Curtis, V. And Cairncross (2003), S. Effect of Washing Hands with Soap on Diarrhoea Risk in the Community: A Systematic Review. Lancet Infectious Diseases 3, pp. 275281. Howard, G(2006).
Groundwater and Public Health, In: Schmoll O. et al. (eds). Protecting Groundwater for Health:Managing the Quality of Drinking-Water Sources, London, International Water Association Publishing, pp. 3-19.

Payment, P., Hunter, P. R. (2001), Endemic and Epidemic Infectious Intestinal Disease and Its Relationship to Drinking

Water, In: Fewtrell L., Bartram J. (eds), Water Quality Guidelines, Standards and Health, London, International Water Association (IWA) Publishing, 61-88pp.

Garneau, C. McNamara, K. and Chung J. (2008), Peristaltic Pump Project, Unpublished Final Project Report, Team D,

ME 340.4, 41pp.

B. Gonzalez ,S. Alzate, J. Cromartie ,K. Hernandez, Advisor: Dr. Andres Tremante (April 7, 2014), Bicycle Powered Water Filtration System, A B.S. Thesis prepared in partial fulfillment of the requirement for the Degree of Bachelor of Science In Mechanical Engineering, Florida International University

A. S. Akinwonmi, S. K. Adzimah, F. Oppong, Department of Mechanical Engineering, University of Mines and Technology, Tarkwa, Ghana. 2012,Pedal Powered Centrifugal Pump Purified Water Supply System, Innovative Systems Design and Engineering ISSN 2222-1727 (Paper) ISSN 2222-2871 (Online) ,Vol 3, No.11

http://www.engineeringtoolbox.com/colebrook-equationd_1031.html

http://www.engineeringtoolbox.com/dynamic-absolutekinematic-viscosity-d_412.html 